\title{
Microplate Assay for Measurement of Histamine Release from Mast Cells
}

BioTechniques 22:958-962 (May 1997)

\author{
Joseph A. Price, III \\ Oklahoma State University \\ College Osteopathic Medicine \\ Tulsa, OK, USA
}

\section{INTRODUCTION}

Although the standard assay for action of pro-inflammatory agents on mast cells is the release of histamine, the spectrofluorometric assay $(7,8)$, often modified (reviewed in Reference 4), is laborious. Alternatives exist, e.g., cytokine release from cultured cells $(6,9)$ or, in some cases, staining with berberine sulfate (1), but each has technical drawbacks. If the histamine release could be done in the 96-well format, and then linked to a 96-well format histamine assay, this would greatly expedite the assay and enhance pharmacological studies using the rat (or human) mast cells. This report includes some technical parameters to facilitate the assay and demonstrates the dynamic range and reproducibility of data for the microplate assay.

\section{MATERIALS AND METHODS}

\section{Reagents}

Glucose, potassium chloride, sodium chloride, O-phthaldialdehyde (OPT, 99\%) and other chemicals were reagent grade (Sigma Chemical, St. Louis, MO and J.T. Baker, Phillipsburg, NJ, USA). Water was prepared with a Milli- $\mathrm{Q}^{\mathrm{TM}}$ system (Millipore, Bedford, MA, USA).

Rat (outbred, 300-400 g, mixed sexes, Sprague Dawley; Harlan Sprague Dawley, Indianapolis, IN, USA) peritoneal cells were lavaged into modified Tyrode's buffer (lacking bicarbonate and divalent cations) buffered with 15 $\mathrm{mM}$ HEPES to $\mathrm{pH} 7.2$ containing $0.1 \%$ (wt/vol) bovine serum albumin (Sigma Chemical). Mast cells were isolated as the fraction recovered from the inter- face of $27.6 \%$ and $20 \%$ Accudenz $^{\circledR}$ (Accurate Chemical \& Scientific, Westbury, NY, USA) prepared according to manufacturer's directions. Before use, the cells were counted by toluidine blue staining (2) in a hemocytometer and diluted into $15 \mathrm{mM}$ HEPES-buffered modified Tyrode's buffer as before, but with $1 \mathrm{mM} \mathrm{CaCl}$ and prewarmed before use. Typically $90 \%-98 \%$ of the cell population stained blue.

\section{Assays}

Particular care is given to minimizing micropipetting errors. Assays for histamine release (after $15 \mathrm{~min}$ at $\left.37^{\circ} \mathrm{C}\right)$ were done in replicate $(n=3-4)$. Typically, each reaction mixture contained $25 \mu \mathrm{L}$ of agonist plus $100 \mu \mathrm{L}$ of cells $\left(1-2 \times 10^{3}\right.$ toluidine blue cells) per well. Cells and assay plates were temperature-adjusted before use. After treatment with agonist for 15-20 min at $37^{\circ} \mathrm{C}$, cell-associated histamine was measured, rather than free histamine, to avoid artifacts from residual agonists. Cells were washed 2 or 3 times by centrifugation for $5 \mathrm{~min}$ at $1000 \mathrm{rpm}$ in the microplates (untreated "V"-bottom) in a Model 269 Rotor and IEC Centrifuge (International Equipment Company, Needham Heights, MA, USA). Then, $100 \mu \mathrm{L}$ of $0.1 \%$ (vol/vol) Triton ${ }^{\circledR} \mathrm{X}$ 100 were added and extracted by a $20-$ min exposure at $37^{\circ} \mathrm{C}$, followed by addition of an equal volume of $14 \%$ trichloroacetic acid (TCA), mixing and precipitation in the cold overnight or until assayed. The samples were centrifuged at $1500 \mathrm{rpm}$ before $75-150 \mu \mathrm{L}$ of supernatant were assayed for histamine.

Samples $(75 \mu \mathrm{L})$ were assayed for histamine with $20 \mu \mathrm{L}$ of $2 N \mathrm{NaOH}, 50$ $\mu \mathrm{L}$ OPT in water (from a stock in 

The reaction was done in microplates at $4^{\circ} \mathrm{C}$ for $35 \mathrm{~min}$ or at room temperature for 4-6 $\mathrm{min}$ by a modified protocol modeled after Shore $(3,7,8)$. The TCA was prepared at a $15 \%$ solution, filtered, titrated against $2 \mathrm{~N} \mathrm{NaOH}$ and then adjusted to achieve a $\mathrm{pH}$ of 12.6 in the reaction mixture containing water in lieu of the OPT solution. The stop solution was $\mathrm{H}_{2} \mathrm{SO}_{4}$ titrated against the reaction mixture so as to achieve a final $\mathrm{pH}$ of 2.5-2.8. Titrations of reagents can be fine-tuned by examining the amount of fluorometric signal generated in a control assay with a known concentration of histamine. To control for a methanol) and a $30-\mu \mathrm{L}$ stop solution.

possible effect of the microplate on reading the assay, the reacted samples were added to cuvettes with $2 \mathrm{~mL}$ of water. In later pilot experiments, samples were read directly in the same plate in which the assay was conducted using a plate reader. Mixing of reagents was by hand; although, in later experiments a platform mixer used briefly was satisfactory. Results are calculated from the cellular histamine after treatment with histamine-releasing agents, expressed relative to buffer-treated controls. Where percentage release is indicated, it is calculated from the amount found in control cells as 1-(experimental cells/control cells).

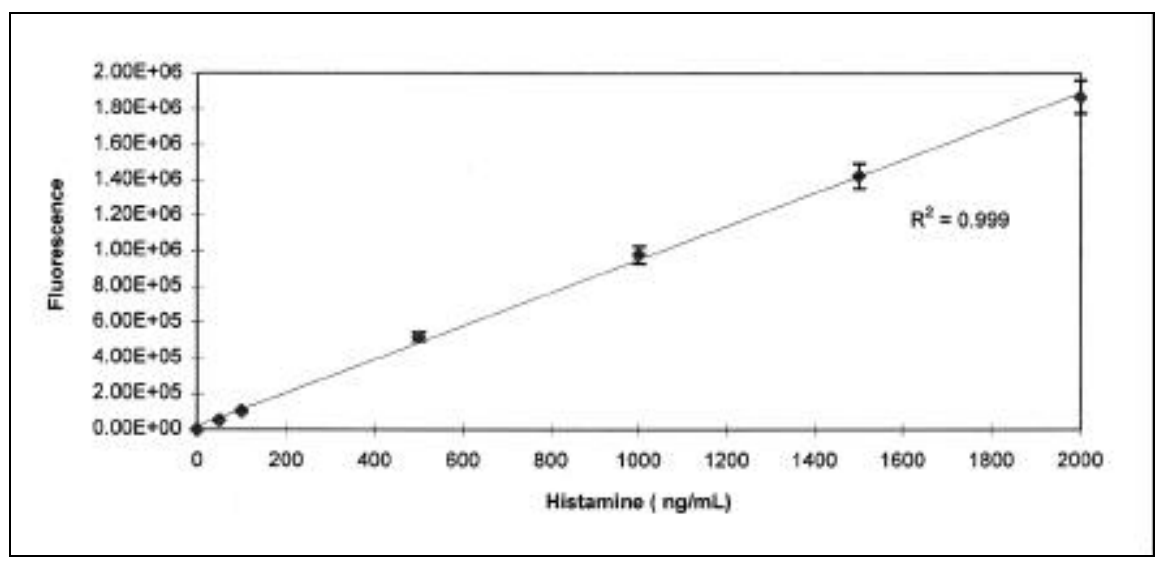

Figure 1. Assay of histamine standards. Histamine standards were assayed and means of groups are shown with the standard errors of the mean $(n=8)$. Data have been adjusted for the assay blank value. After the reaction was completed in microplates, the mixture was read in a cuvette system.

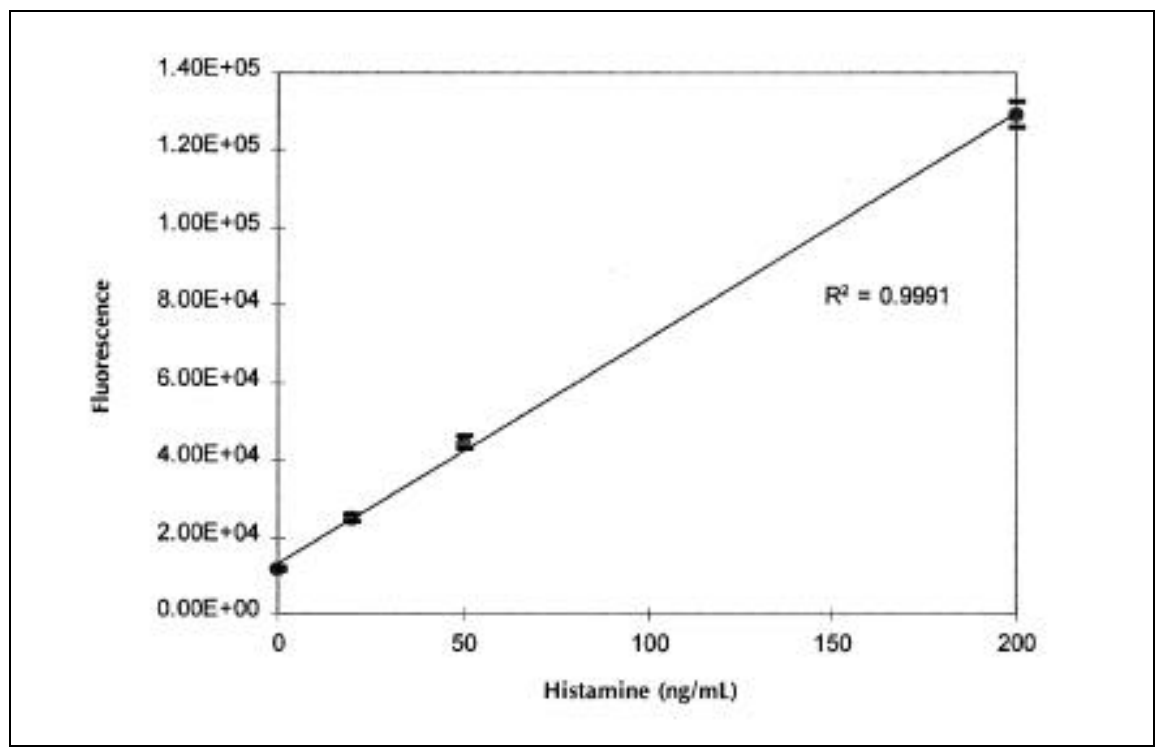

Figure 2. Low-range standard curve of histamine. Data are shown plotted with standard error of the mean $(n=8)$ and are not corrected for blank values in order to better estimate the minimum amount of detectable analyte.

\section{Instrumentation and Analysis}

Initial studies to evaluate the histamine release itself and the performance of the microplate volume for the histamine assay were done in a Model RFM-2001 Spectrofluorometer (Photon Technology International, Monmouth, NJ, USA) with a standard cuvette holder. Samples were excited at $360 \mathrm{~nm}$ and read at $450 \mathrm{~nm}$, and data were collected with a $10-\mathrm{nm}$ band pass at 5 samples/s. Ten 1 -s traces were stored, and the average value over nine seconds was used. Later studies to explore the feasibility of conducting the assay and reading the results in microplates were done with plate readers (Fluorite FL1000 ${ }^{\circledR}$; Dynatech Laboratories, Chantilly, VA and FL500; BioTek Instruments, Winooski, VT, USA). Each value is the result of an independent single reaction of cells with agonist, from histamine release through the histamine assay, performed in replicates; as opposed to multiple histamine assays of a single histamine release reaction. Statistical analysis and plotting were done with Excel ${ }^{\circledR}$ (Microsoft, Redmond, WA, USA). Descriptive statistics, including coefficient of variation (CV) for samples, were done with a number of replicates as indicated above and in the Results section.

\section{RESULTS}

To systematically explore the performance of the assay, three levels of the technology were examined: the histamine spectrofluorometric assay run in microplates (assayed in a conventional cuvette system), release of histamine by cells in microplates and the histamine-release assay conducted wholly in microplates (cell reaction with spectrofluorometric assay including reading).

A standard curve shown in Figure 1 illustrates the range and linearity of the assay done in small volumes. As the largest value tested, $2000 \mathrm{ng} / \mathrm{mL}$, generates a value greater than that from total histamine in the control cells $(2 \times$ $10^{3}$ per well), the detection range is greater than the normal working requirements of the assay and shows excellent linearity. The lower range of the assay is shown in Figure 2. The differ- 
ence in fluorescence between 0 and 20 $\mathrm{ng} / \mathrm{mL}$ is twofold, is significant by an unpaired Student's $t$ test $(P<0.001)$ and is routinely a reliable lower limit for assays should free histamine be measured using this instrumentation.

To examine the reproducibility of the histamine assay and histamine release, the CVs for typical microplate format assays were determined and are shown in Figure 3. For assay of standards as shown in Figures 1 and $2(n=$ 8 ), the CVs average 4\% (Range $1 \%-6 \%)$. Similar values were obtained conducting the histamine assay reactions and reading in various microplates (example shown in Figure 4).

To show examples of best performance, the graphs shown are with all available replicates. However, when asking how much replication is needed for the assay by examining the use of replicates from $n=2$ to $n=10, n=4$ was sufficient to minimize the $\mathrm{CV}$ in these data sets (analysis not shown). Among assays with different types of plates and readers, the average $\mathrm{CV}$ for assays ranged from $4 \%$ to $12 \%$ for the spectrofluorometric assay.

After extraction and TCA precipitation, the samples were stable when refrigerated in TCA for at least a week (not shown). Although it has been reported that background signal in blanks is significantly less if the histamine assay is done at $4^{\circ} \mathrm{C}$ rather than at room temperature (4), this difference was not evident in these experiments (not shown).

Similar standard curves and variance within groups were obtained when evaluating several plate readers and conducting the histamine assay and the reading of the final reaction mixture within the same microplate. Sample data are shown in Figure 4. However, of the few instruments tested, only the newest models provided the combination of sensitivity and dynamic range needed. From a brief survey of three instruments, it was observed that "V"- or flat-bottom clear plastic plates might be functional in some readers, while black or white flat-bottom fluorescence microplates provided better sensitivity. However, the flat-bottom plates have a larger working volume per well; of these, the white were more sensitive than the black, but more prone to spo- radic deviant wells. It was easiest to set the reader for an optimal gain for either the low-range samples for released histamine or the higher range for cellular histamine, while a compromise gain setting was more laborious to determine (not shown) but would put negative and positive controls all within the readable range.

An example of an assay of histamine release by cells, generally too large to do readily by traditional methods, is provided in Figure 5, showing a dose response of the histamine-releasing agent $48 / 80$. When one conducts this histamine release from cells in microplates and then does the histamine microplate assay $(n=3$ or 4$)$, the $\mathrm{CV}$ averages $8 \%$ (range $5 \%-11 \%$ ) in con- trol and experimental groups. Thus, cells washed in microplates before extraction of cell-associated histamine provide consistent values.

\section{DISCUSSION}

Shore indicated that his method would be scaleable to different volumes $(7,8)$. Here we see that the microplate adaptation of the technique can be functional, and thus enable a large number of assays to be done expeditiously. The introduction of microplates, micropipets and centrifuge carriers for microplates has made this feasible. The assay is improved by several adjustments of the reagents (4), coupled with the assay of cellular hist-

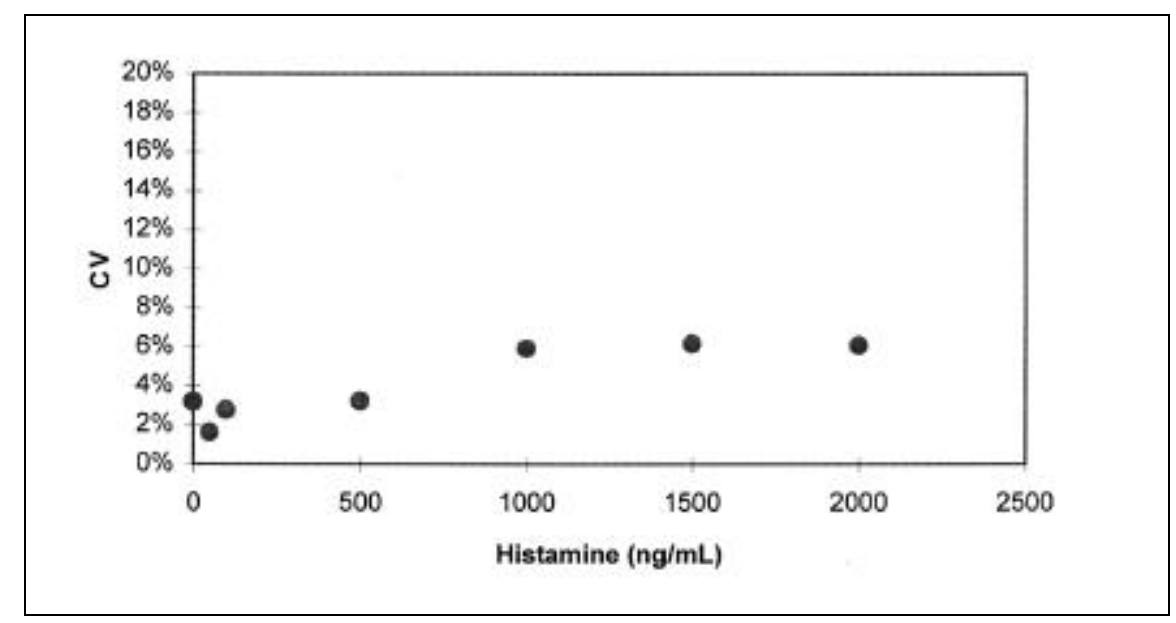

Figure 3. Coefficient of variation for a histamine standard curve. The $\mathrm{CV}$ for the data for each group $(n=8)$ in the standard curve is plotted.

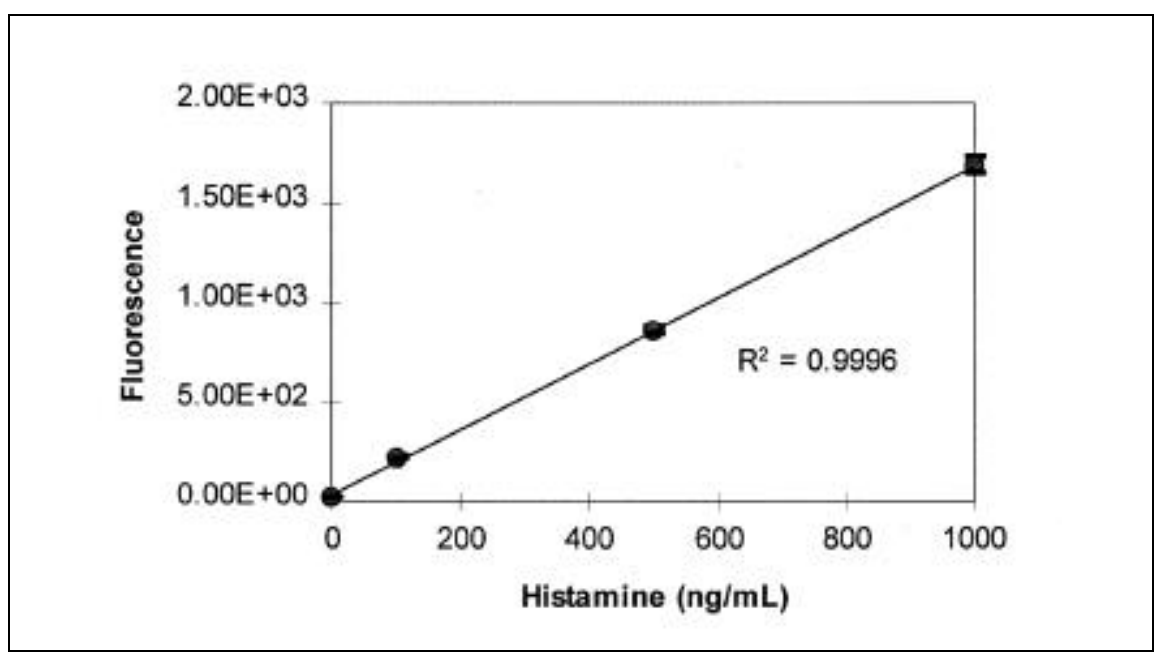

Figure 4. Microplate assay of histamine standards. The assay of standards and reading fluorescence (Fluorlite FL1000) was done in flat-bottom white microplates. The CV was $11 \%-13 \%$ for each dose group $(n=8)$. 
amine from washed cells and transfer steps which are expedited in the microplate format. By evaluating the histamine detection reaction as conducted in wells and measured in cuvettes, we see that, if done with care to volumes pipetted and to evaporation, the data on range and linearity of the assay indicate that the reaction can be conducted accurately in small volumes. The step for cell release of histamine and subsequent washes can be done in microplates also. In this case, since one allows the release reaction to go to completion, minor variations in plate cooling and warming do not seem to be significant factors. A mixture of cells plus agonist presents the difficulty that the agonist can later interfere with the histamine assay (can be detected in the assay). A procedural solution is to wash the cells and then measure the extractable cellular histamine rather than the released free histamine. This is done easily in microplates with appropriate rotors and plate carriers. Conveniently, the steps for the release, cell washing, extraction of cellular histamine and acid precipitation of macromolecules by $7 \%$ TCA are all done in the same plate. The samples can then

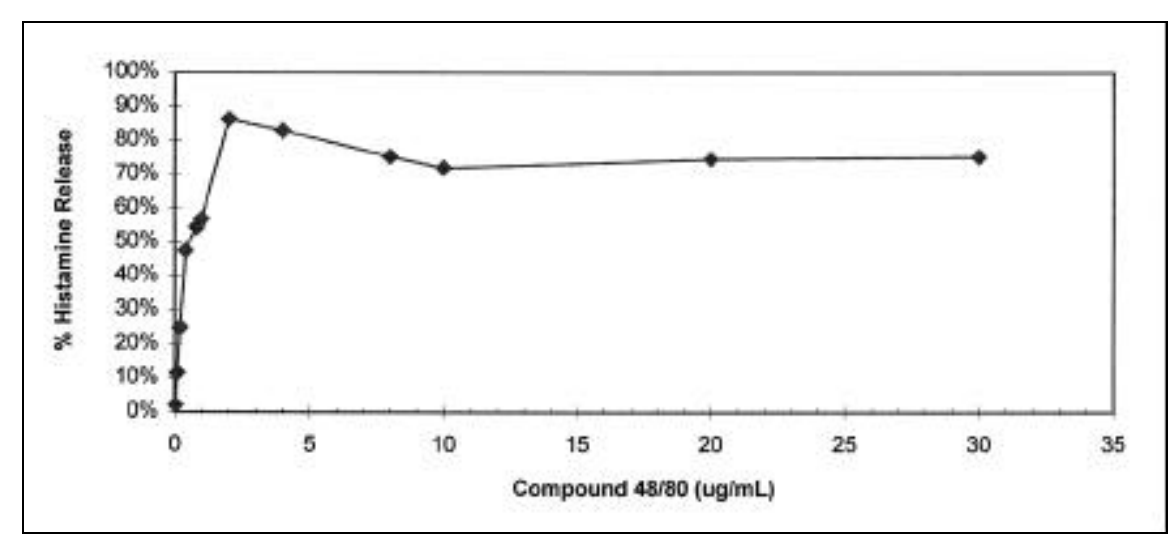

Figure 5. Dose response of compound $48 / 80$. Histamine release by 15 min exposure to the final concentrations of the agent $48 / 80$ is shown $(n=4)$. The $\mathrm{CV}$ ranged from $5 \%-20 \%$, average $\mathrm{CV}=13 \%$. be stored refrigerated in that plate until the plates followed by transfer of each TCA supernatant to the histamine reaction vessels by a multi-well micropipet, expedites this otherwise tedious step. One can adjust the cell numbers used in assay. Furthermore, centrifugation of 
the assay and the volume of TCA supernatant tested to provide an appropriate amount of signal for the detector used. This allows substantial flexibility in adapting the assay to available instrumentation. Because all treatments and replicates use the same cell population, one sees relative differences, simplifying interpretation. Use of a cell population that is essentially all mast cells avoids possible Poisson distribution effects in pipetting the cells into wells. Although qualitative effect experiments may be done with examination of relative release, precise evaluations profit from use of concurrent standard curves.

After evaluating the conduct of the histamine detection reaction in wells (read in cuvettes), the histamine detection assay was run in microplates and the resulting reaction read in the same plate in a plate reader. There was no difference in the magnitude of variance within groups of replicates when reading with the plate reader or transferring reactions into cuvettes to be read. There was some difference in the microplate instruments as to sensitivity and dynamic range. Also, one must choose the appropriate gain setting and microplate type. Useful data were obtained using equipment from Bio-Tek Instruments and Dynatech Laboratories with moderate differences between types of plates. However, substantial instrument and microplate comparisons are beyond the scope of this report.

In a single day, one can effectively conduct a large number of assays using the microplate format assay for measurement of histamine release followed by microplate histamine assay. A twohundred determination experiment (2 plates $\times 96$ wells) can be done in a day. Note that the small volumes do necessitate fastidious mixing and micropipetting techniques. The dose response shown in Figure 5 would then be a single, one-day experiment with one pool of cells, but not in traditional assays (References 3 and 5, for example) as published. Note that this experiment was done with cells exposed to an agonist, then washed before histamine extraction. This is a more generally applicable protocol suitable for studying agonists that would interfere with the histamine assay, and that would pre- clude a simple measurement of histamine released into the media by the cells during treatment with the agonist. In contrast, published experiments are generally done with released, not cellular, histamine, thus greatly simplifying the work. Nevertheless, similar studies $(3,5)$ required pooled data from $4-5$ experiments with 3-4 replicates per dose to reduce variation at each given dose to acceptable levels. The performance data presented here indicate the practicality of the microplate approach with a more generally applicable protocol and compare well with historical data derived from the larger format assays. This adaptation to microplates should greatly expedite mast cell research.

\section{ACKNOWLEDGMENTS}

Financial and administrative support was provided by NIH Grant No. R15 GM46117-01A1, the Department of Biochemistry and Microbiology and Office of Research and Sponsored Programs OSU-COM. Technical support by Marva Volk is gratefully acknowledged. A special acknowledgment is given to Dynatech Laboratories Inc., Bio-Tek Instruments and Perseptive BioSystems, which generously loaned the spectrofluorometric plate readers used for these studies.

\section{REFERENCES}

1.Berlin, G. and L. Enerback. 1984. The dynamics of mast cell secretion studied by vital berberine staining. Agents Actions 14:401404.

2.Bray, R.E. and P.P. VanArsdel. 1961. In vitro histamine release from rat mast cells by chemical and physical agents. Proc. Soc. Exp. Biol. Med. 106:255-259.

3.Botana, L.M., J. Espinosa, N. Elena, C. Segura and P. Fernandes-Otero. 1985. Difference in, and influence of the purification medium on, sensitivity and maximum response of peritoneal and pleural mast cells stimulated by certain polyamines. Agents Actions 16:342-345.

4.Hakanson, R., A.L. Ronnberg and K. Sjolund. 1972. Fluorometric determination of histamine with OPT: optimum reaction conditions and tests of identity. Anal. Biochem. 47:356-370.

5.Mousli, M., C. Bronner, J.L. Bueb, E. Tschirhart, J.P. Gies and Y. Landry. 1989. Activation of rat peritoneal mast cells by Substance P and Mastoparan. J. Pharmacol. Exp. Ther. 250:329-335.
6.Plaut, M., J.H. Pierce, C.J. Watson, J. Hanley-Hyde, R.P. Nordan and W.E. Paul. 1989. Mast cell lines produce lymphokines in response to cross-linkage of $\mathrm{Fc}$ and $\mathrm{RI}$ or to calcium ionophores. Nature 339:64-67.

7.Shore, P.A. 1971. Fluorometric assay of histamine. Methods Enzymol. 17:842-845.

8.Shore, P.A., A. Burkhalter and V.H. Cohn, Jr. 1959. A method for the fluorometric assay of histamine in tissues. J. Pharmacol. 187:182-186.

9.Wodnar-Flipowicz, A., C.H. Heusser and C. Moroni. 1989. Production of the haematopoietic growth factors GM-CSF and interleukin3 by mast cells in response to IgE receptormediated activation. Nature 339:150-152.

Received 12 June 1996; accepted 23 October 1996.

Address correspondence to:

Joseph A. Price III

Department of Biochemistry and Microbiology OSU-COM

$1111 \mathrm{~W} .17$ th Street

Tulsa, OK 74107, USA

Internet: price@vms.ocom.okstate.edu 